\title{
Quinoxaline 1,4-di-N-oxide and the Potential for Treating
}

\section{Tuberculosis}

\author{
E. Vicente ${ }^{1}$, R. Villar ${ }^{1 *}$, B. Solano ${ }^{1}$, A. Burguete ${ }^{1}$, S. Ancizu, B. Zarranz ${ }^{1}$, A. Jaso ${ }^{1}$, A. \\ Marín $^{1}$, S. Pérez-Silanes ${ }^{1}$, I. Aldana ${ }^{1}$, R. Goldman ${ }^{2}$, A. Monge ${ }^{1}$ \\ Unidad de Investigación y Desarrollo de Medicamentos, Centro de Investigación en Farmacobiología \\ Aplicada (CIFA), University of Navarra, C/ Irunlarrea s/n, 31008 Pamplona, Spain ${ }^{1}$, National Institutes \\ of Health, Division of Microbiology and Infectious Diseases, Bethesda, MD, USA ${ }^{2}$
}

Keywords: Tuberculosis, quinoxaline 1,4-di- $N$-oxide, Mycobacterium.

*Address correspondence to this author at Unidad de Investigación y Desarrollo de Medicamentos, Centro de Investigación en Farmacobiología Aplicada (CIFA), University of Navarra, C/ Irunlarrea s/n, 31008 Pamplona, Spain. Tel.: +34 948 425653; Fax +34 948 425652; e-mail: cifa@unav.es 


\begin{abstract}
New drugs active against drug-resistant tuberculosis are urgently needed to extend the range of TB treatment options to cover drug resistant infections. Quinoxaline derivatives show very interesting biological properties (antibacterial, antiviral, anticancer, antifungal, antihelmintic, insecticidal) and evaluation of their medicinal chemistry is still in progress. In this review we report the properties and the recent developments of quinoxaline $1,4-\mathrm{di}-\mathrm{N}$ oxide derivatives as potential anti-tuberculosis agents. Specific agents are reviewed that have excellent antitubercular drug properties, are active on drug resistant strains and nonreplicating mycobacteria. The properties of select analogs that have in vivo activity in the low dose aerosol infection model in mice will be reviewed.
\end{abstract}




\section{INTRODUCTION}

Tuberculosis (TB), caused by Mycobacterium tuberculosis, is a respiratory transmitted disease affecting nearly $32 \%$ of the world's population, more than any other infectious disease. Since the beginning of human history tuberculosis has been a companion of mankind. However, the impact of tuberculosis on morbidity and mortality has varied widely during the centuries. There were an estimated 8.8 million new TB cases in 2005. A total of 1.6 million people died of TB, including 195000 patients infected with HIV [1].

Since the beginning of the clinical treatment of tuberculosis with streptomycin it was observed that the bacillus was capable of rapidly developing drug resistance [2]. By the 1950s drug combination regimens were established to prevent drug resistance [3]. Currently, multidrug-resistant (MDR) TB presents a high incidence, with rates varying widely between different countries and regions [4]. The continuing emergence of multidrug-resistant strains of M. tuberculosis (MDR-TB) will inevitably make it more difficult in the future to control TB in the global setting [5]. Another important issue related to the increasing spread of tuberculosis is the coexistence of HIV with TB. HIV infected patients who progress to AIDS are at high risk for infection with TB and other mycobacteria (such as $M$. avium). While M. avium does not usually cause disseminated disease in healthy individuals, in immunocompromised patients, such as AIDS, disseminated disease is common [6]. So the pandemic of AIDS and the evidence of its association with tuberculosis is now of serious concern [7]. The development of resistance by $M$. tuberculosis to commonly used anti-tuberculosis drugs, the increasing incidences of disease in immuocompromised patients, and longer durations of therapy that are required as a result of resistance development, highlights the need for new drugs to extend the range of effective TB treatment options.

The Tuberculosis Antimicrobial Acquisition and Coordinating Facility (TAACF) was established in 1994 by the National Institute of Allergy and Infectious Diseases [8] in order to 
provide drug testing facilities to help in the discovery of new antitubercular drugs. The program, managed by Southern Research Institute (Birmingham, AL), assists commercial, academic and government laboratories worldwide in identifying new chemical classes of compounds for evaluation in in vitro and in vivo models. The purpose of the screening program is to provide a resource whereby new experimental compounds can be tested for their ability to inhibit the growth of virulent $M$. tuberculosis. These screening activities have resulted in several promising agents that have reached advanced stages of testing [9]. Chart 1 shows the preliminary levels of biological assays and cut-offs applied by TAACF for progression of the compounds in tuberculosis drug screening program.

The quinoxaline derivatives are a class of compounds that show very interesting biological properties and there is active interest in their medicinal chemistry. The oxidation of both nitrogens of this heterocyclic system, in order to obtain quinoxaline 1,4-di- $\mathrm{N}$-oxide derivatives, increases the number of biological properties enormously [10]. In fact, the quinoxaline 1,4-di- $N$-oxides were known as potent antibacterial agents since the 1940s [1115], and subtherapeutic levels have been used as animal growth promotors in feed additives (Figure 1) [16-20]. Specific derivatives also show selective cytotoxicity against hypoxic cells present in solid tumors [21]. Furthermore, recent studies have demonstrated that quinoxaline 1,4-di- $N$-oxides are endowed with antimycobacterial, antiprotozoal [22,23], anticandida [24,25] activities and mutagenic properties [26-28], depending on specific chemical features. In the last two decades many mono- and di- $\mathrm{N}$-oxides of the quinoxaline ring subunit were reported [29]. Data from studies of quinoxaline 1,4-di- $\mathrm{N}$-oxide derivatives as antitubercular drug candidates has shown that specific derivatives show hold promise in the treatment of TB $[30,31]$. 


\section{GENERAL BACKGROUND}

Isoniazid and pyrazinamide are based on pyridine and pyrazine rings respectively, both classical bioisosters. The fusion of these aromatic heterocycles with a benzene moiety leads to benzo[b]pyridine and benzo[b]pyrazine, also know as quinoline and quinoxaline rings. An example of quinoline derivatives is compound TMC207 (also known as R020790) which is in clinical trials for treating tuberculosis [32]. Quinolone derivatives arise from oxidation of quinoline moiety; this heterocycle is the main scaffold of well-know fluoroquinolones such as ciprofloxacin [33]. As shown figure 2, our design of new antitubercular drug is based on chemical structural resemblance.

In addition, quinoxalines and their mono- and di- $\mathrm{N}$-oxide derivatives display a broad range of biological activities [10] and quinoxaline di- $\mathrm{N}$-oxides are known to undergo bioreductions under hypoxia causing DNA damage [26-28] and likely other cellular damage. Given the known activity of other classes of bioreductive agents (e.g. metronidazole, PA-824 and OPC-67683), it appeared logical to us to evaluate our group of structures against mycobacteria [9].

Over 87,000 compounds have been supplied to TAACF, of which only $0.9 \%$ have shown a good in vitro activity/toxicity ratio [9]. One of five lead compound series which were identified and are currently been pursued under the TAACF program is the series of quinoxaline 1,4-di- $N$-oxide derivatives. Over 500 quinoxaline derivatives from our laboratory were tested by the TAACF program, including simple substituted quinoxalines and their corresponding 1,4-di- $\mathrm{N}$-oxides. Many of these compounds possess excellent antitubercular activity, and the range of possible substituents affords an opportunity to tailor both the pharmacokinetic and activity profiles [9].

As a part of our antituberculosis research project, we have synthesized different series of quinoxaline-1,4-di-N-oxide derivatives, with a great variety of substituents in positions 2,3 , 6 and 7 (Figure 3). Regarding the 2 position, where the main group is linked, our team has 
principally worked with carbonitrile, amide, ketone and ester derivatives. The groups studied in position 3 are, among others, methyl, amine, trifluoromethyl, piperazinyl and phenyl groups. Finally, the substitutions of the hydrogens of positions R6 and/or R7 by fluorine, chlorine, methyl, trifluoromethyl and methoxy groups allowed us to obtain a great variety of compounds. These studies have facilitated a wide-ranging structure-activity relationship (SAR) analysis.

The first publications regarding quinoxaline derivatives as anti-Mycobacterium agents date back to the end of the 1990s [34-36]. Herein, our group reported interesting results of 2quinoxalinecarbonitrile derivatives obtained from the first screening; Carta's team did the same with quinoxaline-2-one derivatives [37]. During these past few years, our group studied the influence of the 1,4-di- $N$-oxide groups in quinoxaline ring on the antimycobacterial activity, confirming their importance to increase the activity [34-36].

In the early 2000s, positive results from further studies were obtained and several new quinoxaline 1,4-di- $\mathrm{N}$-oxide derivatives were synthesized and tested against Mycobacterium tuberculosis. The 2-quinoxalinecarbonitrile derivatives appeared to be quite toxic $[38,39]$; thus, the replacement of the carbonitrile group with a carboxamide [40], acetyl, benzoyl [41] or carboxylate groups [42] was proposed.

A group of thirty-one 3-methylquinoxaline-2-carboxamide 1,4-di- $\mathrm{N}$-oxide derivatives was prepared and tested [40]. Eight showed a MIC value lower than $6.25 \mu \mathrm{g} / \mathrm{mL}$ although only 3 presented enough selectivity and good results in macrophage assay in order to merit continuation of their study. We should point out the interesting antimycobacterial activities shown by certain 3-methyl- $N$-phenylquinoxaline-2-carboxamide 1,4-di- $N$-oxide derivatives, particularly the compounds with a chlorine atom in 7 position (3) and corresponding nonsubstituted derivatives (1 and 2 ) which showed the best results (Figure 4). With regard to the benzene moiety, greater effectiveness resulted for the ortho-methyl substituents ( 2 and 3). 
Among twenty-seven 2-acetylquinoxaline 1,4-di- $\mathrm{N}$-oxide and seven 2benzoylquinoxaline 1,4-di- $N$-oxide derivatives [41], eighteen demonstrated MIC values equal or better than the first cut-off established by the TAACF. Six of these derivatives also showed good selectivity and maintained activity in the macrophage assay, among which stand out compounds 4-6 (Figure 5), exhibiting $\mathrm{EC}_{90} / \mathrm{MIC}$ values between 0.79 and 3.13 .

Twenty-two of the twenty-nine 2-quinoxalinecarboxylate 1,4-di- $\mathrm{N}$-oxide derivatives evaluated possessed improved MIC values [42]. In addition, fifteen were selective as assessed by the cytotoxicity assay and were active in the macrophage assay. The results from the in vitro assays show that of the series tested ethyl and benzyl 3-methylquinoxaline-2carboxylate 1,4-di- $N$-oxide derivatives with the chlorine group in position 7 of the benzene moiety ( 8 and 10$)$ and the unsubstituted derivatives (7 and 9 ) had the best antimycobacterial activity, showing $\mathrm{EC}_{90} / \mathrm{MIC}$ values between 0.01 and 2.30 (Figure 6). These new quinoxaline 1,4-di- $N$-oxide derivatives emerged as new lead candidates for the treatment against tuberculosis because of their potency, selectivity and low cytotoxicity.

Meanwhile, other groups continued their work with reduced quinoxaline derivatives as antimycobacterial agents [43-45]. Kunes et al. studied a series of 3-methyl-2alkylsulfanylquinoxalines, but none were active against $M$. tuberculosis. Seitz and coworkers prepared 9 quinoxaline-2-carboxylates, but only two achieved the MIC values of $6.25 \mu \mathrm{g} / \mathrm{mL}$; Guillon's group focused on pyrrolo[1,2-a]quinoxaline-carboxylic acid hydrazide derivatives and, again, only two compounds reached the first cut-off (MIC $<6.25 \mu \mathrm{g} / \mathrm{mL}$ ).

Carta's team published a series of 3-methylquinoxaline 1,4-di- $N$-oxide derivatives with a phenylthio, phenylsulfonyl or phenylsulfinyl linked in R2 position of quinoxaline subunit. They completed this work studying 6,7-difluoroquinoxaline derivatives, analogues to the previous compounds, in which the phenylthio group was substituted for benzylamino or phenylamino (Figure 7). The series of 3-methyl-2-phenylthioquinoxaline 1,4-di- $\mathrm{N}$-oxide derivatives presented the best MIC data, ranging between 0.39 and $0.78 \mu \mathrm{g} / \mathrm{mL}$, whereas the oxidation of 
sulphur bridge to yield phenylsulfinyl and phenylsulfonyl derivatives or its replacement with benzylamino or phenylamino group slightly reduces its activity $[24,25]$.

\section{RECENT DEVELOPMENTS}

These in vitro results indicate that 1,4-di- $N$-oxide quinoxalines hold promise for the treatment of tuberculosis. Therefore, an extended evaluation of the in vitro and in vivo antitubercular activity of most interesting quinoxaline 1,4-di- $N$-oxide derivatives was performed.

\section{Amide derivatives}

MIC values for the most potent amide derivatives from our previous studies (1-3) (Figure 4) were determined against different single-drug resistant strains of $M$. tuberculosis. In general, the three derivatives showed good MIC values against resistant strains. The MBCs against strain $\mathrm{H}_{37} \mathrm{Rv}$ of compounds $\mathbf{1}$ and 2 were determined. Derivative $\mathbf{1}$ could be considered bactericidal but, on the other hand, compound 2, which showed higher MBC/MIC ratios for $\mathrm{H}_{37} \mathrm{Rv}$, indicated bacteriostatic rather than bactericidal activity [30].

\section{$\underline{\text { Ketone derivatives }}$}

The ketone derivatives 4-6 (Figure 5) were subjected to the following set of tests: determination of MIC against different SDR strains of $M$. tuberculosis, MBC and in vivo efficacy testing, including the determination of oral bioavailability and the MTD. Almost all of these derivatives displayed good inhibitory activity against resistant strains. Results showed that the most moderate activity was observed against the CIP-resistant strain. The susceptibilities of RIF-, TAC-, EMB- and PAS resistant strains were comparable to that of $\mathrm{H}_{37} \mathrm{Rv}$, with ratios of MICs against resistant and non-resistant strains about 1 . This indicates that there is no cross-resistance with the current anti-TB drugs supporting the premise that 1,4-di- $N$-oxide quinoxaline derivatives have a novel mode of action unrelated to the currently 
used antitubercular drugs. These results are promising for the development of new effective compounds against the growing number of drug resistant strains [30]. Compounds 4 and 6 could be considered to be bactericidal due to the low MBC/MIC ratios obtained [30].

In addition, specific derivatives were further evaluated in a series of in vivo assays and compound 6 (designated TAACF 118845) was active in reducing CFU counts in both the lung and spleen of infected mice following oral administration (Figure 8). This in vivo efficacy is comparable to clinically used TB drugs, although a relatively high dose of compounds was required to obtain equivalent reductions in lung CFU [30]. Compound 6 was active in vivo via oral administration when dosed at 100 or $300 \mathrm{mg} / \mathrm{kg}$ and in vivo cidal activity was indicated at $300 \mathrm{mg} / \mathrm{kg}$ dosing (i.e. CFU counts following 9 days of therapy were lower that the CFU counts at the initiation of therapy, Figure 8).

This compound is most likely bioreduced to an active metabolite and is active on PA824 resistant $M$. bovis, thereby indicating that the pathway of bioreduction/activation was different from PA-824, a bioreducible nitroimidazole in clinical trials $[33,46]$. In addition compound 6 was tested against non-replicating bacteria (NRP) adapted to low oxygen and showed very good activity, indicating that activation occurred in both growing and nonreplicating bacteria leading to cell death [30].

Therefore, the activity of compound $\mathbf{6}$ is unique in that it is 1) bactericidal; 2) active on single-drug resistant strains, 3) and more importantly active on poly-drug resistant clinical isolates, MDR-TB, including strains with resistance to additional TB drugs and quinolones; 4) orally bioavailable and strongly active in vivo, in a murine model of tuberculosis infection; 5) active against PA-824 resistant strains of $M$. bovis with defined resistance determinants; and 6) active on non-replicating persistent mycobacteria. This later activity may prove important for attaining cures in a shorter amount of time, and this is being further evaluated in vitro and in vivo [30]. 


\section{Ester derivatives}

Following the protocol for the ketone derivatives, several ester compounds were subjected to the same in vitro and in vivo assays.

The MIC against different single-drug resistant strains of $M$. tuberculosis and in vivo efficacy testing of the most potent compounds from previous studies were evaluated. Similar to the results for the ketone derivatives there is little to no cross-resistance with the current anti-TB drugs as all compounds showed ratios of MICs against resistant and non-resistant strains of about 1 [31].

Compound $\mathbf{8}$ is most likely bioreduced to an active metabolite and is active on PA-824 resistant $M$. bovis, thereby indicating that the pathway of bioreduction/activation was different from PA-824, a bioreducible nitroimidazole in clinical trials [33,46]. Quinoxaline $\mathrm{N}$-oxides are likely activated via bioreduction in bacteria. Compound $\mathbf{8}$ is most likely bioreduced to an active metabolite and is active on PA-824 resistant M. bovis, thereby indicating that the pathway of bioreduction/activation was different from PA-824via of the nitroimidazole PA-824 was used to compare if compound $\mathbf{8}$ was activated through the same pathway. Again, the quinoxaline derivative 8 was active on all PA-824 resistant M. bovis strains tested showing lack of cross-resistance and supporting a different pathway of drug activation. This compound also showed activity under anaerobic conditions in a Low Oxygen Recovery Assay (LORA).

The in vivo activity of ethyl 7-chloroquinoxaline derivative (8, designated TAACF 151985) was evaluated at oral doses of 25,100 and $300 \mathrm{mg} / \mathrm{kg}$. This compound was active in the lung and spleen (Figure 9) at 100 and $300 \mathrm{mg} / \mathrm{kg}$ with a reduction of the CFU of 2.03 and 5.58 (lung) and 2.72 and 5.51 (spleen), respectively [31]. As with compound 6, compound 8 appeared cidal in vivo when dosed at $300 \mathrm{mg} / \mathrm{kg}$ (Figure 9).

Several structural modifications were introduced onto the lead compounds of the series of 3-methylquinoxaline-2-carboxylate 1,4 -di- $\mathrm{N}$-oxide derivatives [47]. Homologation of the substituents linked at C-3 of quinoxaline scaffold was obtained by the replacement of a 
methyl with a phenyl group, keeping the ethyl carboxylate group linked to C-2 of the quinoxaline subunit. Variations of the electronic profile of the group $\mathrm{W}$ linked to the para position of the phenyl moiety were carried out [48]. All of the modifications were conducted in order to establish the contributions of electronic and steric parameters for the optimization of the lead compounds. Certain parameters of potency, cytotoxicity and selectivity (levels 1 and 2) were established for the fourteen synthesized derivatives. The unsubstituted derivatives in positions R6/R7 and the 7-methyl derivative demonstrated selectivity indexes greater than the established cut-off $(\mathrm{SI}>10)$ and were selected for more additional studies. One compound with unique activity is ethyl 3-(4'-fluoro)phenylquinoxaline-2-carboxylate 1,4-di- $\mathrm{N}$-oxide, $\mathbf{1 1}$ (Figure 10) [47].

\section{Other derivatives}

Our research group designed other quinoxaline 1,4-di- $\mathrm{N}$-oxide derivatives [49] in order to combat other diseases such as malaria [50-54] and cancer $[55,56]$ which were also assayed as antimycobacterial candidates.

Twenty seven 2-alkylcarbonyl- and thirty 2-arylcarbonyl-3-trifluoromethylquinoxaline 1,4-di- $N$-oxide derivatives, designed as anticancer [55,56] and antiplasmodial agents $[51,52]$, were tested against $M$. tuberculosis. Among these 57 compounds, only eight of them did not pass the first screening but almost all of them were not selective enough $(S \mid<10)$ to move forward. The four derivatives with $\mathrm{SI}>10$ were all alkylcarbonyl derivatives (the least potent against cancer cell lines), outstanding 6,7-dichloro-2-isobutyryl-3-trifluoromethylquinoxline 1,4-di-N-oxide, 12 (Figure 9).

Our group synthesized seventy two 3-arylquinoxaline-2-carbonitrile 1,4-di- $\mathrm{N}$-oxide derivatives, designed as antiplasmodial agents [50,53,54]. The activity against $M$. tuberculosis of all of them were established, showing that sixty-nine derivatives attained the first cut-off (MIC $<6.25 \mu \mathrm{g} / \mathrm{mL}$ ). Moreover, forty-five of these sixty-nine compounds showed an 
MIC value equal to or less than $0.2 \mu \mathrm{g} / \mathrm{mL}$, a value on the order of MIC of rifampicin (RIF). Cytotoxicity and selectivity of thirty-seven analogs were determined revealing that the fluorinated derivatives (13-18) were the least cytotoxic and the most selective compounds (Figure 10). One compound of particular interest is 7-methyl-3-(4'-fluoro)phenylquinoxaline-2carbonitrile 1,4-di- $N$-oxide, 14, with $\mathrm{MIC}<0.2 \mu \mathrm{g} / \mathrm{mL}$ and $\mathrm{SI}>500$ [47].

\section{Mycobacterium avium}

Infections caused by $M$. tuberculosis and $M$. avium complex are the most commonly reported opportunistic bacterial infections in people with HIV disease [57]. M. avium is a human pathogen that causes infection in immunocompetent as well as immunocompromised patients [58]. The TAACF has tested some of our selected compounds for activity against $M$. avium but only one was active. This compound, 6, the ethyl 7-chloro-3-methylquinoxaline-2carboxylate 1,4 -di- $N$-oxide demonstrated MIC $\leq 8 \mu \mathrm{g} / \mathrm{mL}$ for 4 of the 5 strains tested. The reason for lack of, or reduced activity on $M$. avium could be due to differences in potential activating enzymes and or uptake of compounds into the bacteria.

\section{CONCLUSIONS}

Over the past years quinoxaline 1,4 -di- $N$-oxide derivatives were found to possess activity against $M$. tuberculosis. Continued evaluation of in vitro antimycobacterial activity and cytotoxicity of our quinoxaline 1,4-di- $N$-oxide series, allowed identification of novel antitubercular candidates based on their potency, selectivity and low cytotoxicity, making them valid new lead for synthesizing additional analogs that might improve the antitubercular activity both in vitro and in vivo. Recently some select analogs were found active against a panel of single-drug-resistant strains and in the TAACF macrophage model. Two derivatives, compounds 6 and 8, proved efficacious in vivo in a murine model of low dose aerosol infection. Moreover, theses two compounds also showed activity against non-replicating 
bacteria. If the bactericidal activity and activity on NRP bacteria in vitro translate to in vivo conditions, quinoxaline 1,4-di- $N$-oxides may lead to shortened therapy, because the presence of NRP bacteria is believed to be a major factor responsible for the prolonged nature of antitubercular therapy. In conclusion, quinoxaline 1,4-di- $N$-oxides represent a new class of orally active antitubercular drugs.

\section{ACKNOWLEDGEMENTS}

Antimycobacterial data was provided by the Tuberculosis Antimicrobial Acquisition and Coordinating Facility (TAACF) through a research and development contract with the U.S. National Institute of Allergy and Infectious Diseases (NIAID): N01-AI-95364 and N01-AI15449 to Southern Research Institute, Birmingham, AL, and N01-AI-95385 to Colorado State University, Fort Collins, CO. 


\section{ABBREVIATIONS}

\begin{tabular}{|c|c|c|}
\hline AIDS & $=$ & Acquired immunodeficiency syndrome \\
\hline CFU & $=$ & Colony-forming unit \\
\hline CIP & $=$ & Ciprofloxacin \\
\hline EC & $=$ & Effective concentration \\
\hline EMB & $=$ & Ethambutol \\
\hline Gl & $=$ & Growth inhibition \\
\hline HIV & $=$ & Human immunodeficiency virus \\
\hline INH & $=$ & Isoniazid \\
\hline LORA & $=$ & Low oxygen recovery assay \\
\hline MBC & $=$ & Minimum bactericidal concentration \\
\hline MDR-TB & $=$ & Multiple drug resistant tuberculosis \\
\hline MIC & $=$ & Minimum inhibitory concentration \\
\hline MTD & $=$ & Maximum tolerated dose \\
\hline NIAID & $=$ & National Institute of Allergy and Infectious Diseases \\
\hline NRP & $=$ & Non-replicating persistent \\
\hline PAS & $=$ & p-aminosalicylic acid \\
\hline RIF & $=$ & Rifampin \\
\hline SDR & $=$ & Single drug resistant \\
\hline SI & $=$ & Selectivity index \\
\hline TAACF & $=$ & Tuberculosis Antimicrobial Acquisition and Coordinating Facility \\
\hline TAC & $=$ & Thiacetazone \\
\hline TB & $=$ & Tuberculosis \\
\hline
\end{tabular}




\section{REFERENCES}

Sheet,

№

104.

2007

http://www.who.int/tb/publications/global report/2007/pdf/full.pdf.

[2] Mitchison, D.A. Am. J. Respir. Crit. Care Med., 2005, 171, 699.

[3] Saltini, C. Respir. Med., 2006, 100, 2085.

[4] Fatkenheuer, G.; Taelman, H.; Lepage; P.; Schwenk, A.; Wenzel, R. Diagn. Microbiol. Infect. Dis., 1999, 34, 139.

[5] Ballell, L.; Field, R.; Duncan, A.K; Young, R.J. Antimicrob. Agents Chemother., 2005, 49, 2153.

[6] Inderlied, C.B.; Kemper, C A.; Bermudez, L.E.M. Clin. Microbiol. Rev., 1993, 6, 266.

[7] Nayyar, A.; Jain, R. Curr. Med. Chem., 2005, 12, 1873.

[8] Tuberculosis Antimicrobial Acquisition and Coordinating Facility. http://www.taacf.org/.

[9] Goldman, R.C.; Laughon, B.E.; Reynolds, R.C.; Secrist III, J.A.; Maddry; Guie, M.A.; Poffenberger, A.C.; Kwong, C.A.; Ananthan, S. Infect. Disord. Drug Targets, 2007, 7, 92.

[10] Carta, A.; Corona, P.; Loriga, M. Curr. Med. Chem., 2005, 12, 2259.

[11] Mcllwain, H. J. Chem. Soc., 1943, 322.

[12] Wiedling, S. Acta Pathol. Microbiol. Scand., 1945, 22, 379.

[13] Frisk, A.R.. Acta Med. Scand., 1946, 125, 487.

[14] Iland, C.N. Nature, 1948, 161, 1010-1010.

[15] Coulthard, C.E; Hale, L.J. Br. J. Pharmacol. Chem., 1955, 10, 394.

[16] Cihak, R.; Vontorkova, M. Mutat. Res., 1985, 144, 81.

[17] Cihak, R.; Vontorkova, M. Mutat. Res., 1985, 147, 289.

[18] Cihak, R.; Vontorkova, M. Mutat. Res., 1983, 117, 311. 
[19] Cihak, R.; Sr, V. Mutat. Res., 1983, 116, 129.

[20] Novacek, L.; and Polasek, L. Biol. Chem. Zivocisne, 1982, 18, 17.

[21] Gali-Muhtasib, H.U.; Haddadin, M.J.; Rahhal, D.N.; Younes, I.H. Oncol. Rep., 2001, 8, 679.

[22] Aguirre, G.; Cerecetto, H.; Di Maio, R.; Gonzalez, M.; Alfaro, M.E.M; Jaso, A.; Zarranz, B.; Ortega, M.A.; Aldana, I.; Monge-Vega, A. Bioorg. Med. Chem. Lett., 2004, 14, 3835.

[23] Urquiola, C.; Vieites, M.; Aguirre, G.; Marin, A.; Solano, B.; Arrambide, G.; Noblia, P.; Lavaggi, M.L.; Torre, M.H.; Gonzalez, M.; Monge, A.; Gambino, D.; H. Cerecetto, H. Bioorg. Med. Chem., 2006, 14, 5503.

[24] Carta, A.; Paglietti, G.; Rahbar Nikookar, M.E.; Sanna, P.; Sechi, L.; Zanetti, S. Eur. J. Med. Chem., 2002, 37, 355.

[25] Carta, A.; Loriga, M.; Paglietti, G.; Mattana, A.; Fiori, P.L.; Mollicotti, P.; Sechi, L.; Zanetti, S. Eur. J. Med. Chem., 2004, 39, 195.

[26] Ganley, B.; Chowdhury, G.; Bhansali, J.; Daniels, J.S.; Gates, K.S.. Bioorg. Med. Chem., 2001, 9, 2395.

[27] Chowdhury, G.; Kotandeniya, D.; Daniels, J.S.; Barnes, C.L.; Gates, K.S. Chem. Res. Toxicol., 2004, 17, 1399.

[28] Azqueta, A.; Pachon, G.; Cascante, M.; Creppy, E.E.; de Cerain, A.L.. Mutagenesis, 2005, 20, 165.

[29] Brown, D.J.; Taylor, E.C.; Wipf, P. Quinoxalines. Supplement II, Wiley \& Sons: New York, 2004.

[30] Villar, R.; Vicente, E.; Solano, B.; Perez-Silanes, S.; Aldana, I.; Maddry, J.A.; Lenaerts, A.J.; Franzblau, S.G.; Cho, S.-H.; Monge, A.; Goldman, R.C. J. Antimicrob. Chemother., 2008, 62, 547. 
[31] Vicente, E.; Villar, R.; Burguete, A.; Solano, B.; Perez-Silanes, S.; Aldana, I.; Maddry, J.A..; Lenaerts, A.J.; Franzblau, S.G.; Cho, S-H.; Monge, A.; Goldman, R.C.. Antimicrob. Agents Chemother., 2008, 52, 3321.

[32] Andries, K.; Verhasselt, P.; Guillemont, J.; Gohlmann, H.W.H.; Neefs, J.M.; Winkler, H.; Van Gestel, J.; Timmerman, P.; Zhu, M.; Lee, E.; Williams, P.; de Chaffoy, D.; Huitric, E.; Hoffner, S.; Cambau, E.; Truffot-Pernot, C.;. Lounis N.; Jarlier, V.. Science, 2005, 307, 223.

[33] Sacchettini, J.C.; Rubin E.J.; Freundlich, J.S. Nature Reviews Microbiology, 2008, 6, 41.

[34] Montoya, M.E.; Sainz, Y.; Ortega, M.A.; De Cerain, A.L.; Monge, A. Farmaco, 1998, 53, 570.

[35] Ortega, M.A.; Sainz, Y.; Montoya, M.E.; De Cerain, A.L.; Monge, A. Pharmazie, 1999, 54, 24.

[36] Sainz, Y.; Montoya, M.E.; Martinez-Crespo, F.J.; Ortega, M.A.; De Cerain, A.L.; Monge, A. Arzneim.-Forsch., 1999, 49, 55.

[37] Sanna, P.; Carta, A.; Loriga, M.; Zanetti, S.; Sechi, L. Farmaco, 1999, 54, 169.

[38] Ortega, M.A.; Montoya, M.E.; Jaso, A.; Zarranz, B.; Tirapu, I.; Aldana, I.; Monge, A. Pharmazie, 2001, 56, 205.

[39] Ortega, M.A.; Sainz, Y.; Montoya, M.E.; Jaso, A.; Zarranz, B.; Aldana, I.; Monge, A. Arzneim.-Forsch., 2002, 52, 113.

[40] Zarranz, B.; Jaso, A.; Aldana, I.; Monge, A. Bioorg. Med. Chem., 2003, 11, 2149.

[41] Jaso, A.; Zarranz, B.; Aldana, I.; Monge, A. Eur. J. Med. Chem., 2003, 38, 791.

[42] Jaso, A.; Zarranz, B.; Aldana, I.; Monge, A. J. Med. Chem., 2005, 48, 2019.

[43] Kunes, J.; Spulak, M.; Waisser, K.; Slosarek, M.; Janota, J. Pharmazie, 2000, 55, 858.

[44] Seitz, L.E.; Suling, W.J.; Reynolds, R.C. J. Med. Chem., 2002, 45, 5604.

[45] Guillon, J.; Reynolds, R.C.; Leger, J.M.; Guie, M.A.; Massip, S.; Dallemagne, P.; Jarry, C. J. Enzym. Inhib. Med. Chem., 2004, 19, 489. 
[46] Manjunatha, U.H.; Boshoff, H.; Dowd, C.S.; Zhang, L.; Albert, T.J.; Norton, J.E.; Daniels, L.; Dickl, T.; Pang, S.S.; Barry, C.E.. Proc. Natl. Acad. Sci. U. S. A., 2006, $103,431$.

[47] Vicente, E.; Pérez-Silanes, S.; Lima, L.M.; Ancizu, S.; Burguete, A.; Solano, B.; Villar, R.; Aldana, I.; Monge, A. Bioorg. Med. Chem., 2009, 17, 385.

[48] Lima, L.M.; Zarranz, B.; Marín, A.; Solano, B.; Vicente, E.; Pérez-Silanes, S.; Aldana, I.; Monge, A. J. Heterocycl. Chem., 2005, 42, 1381.

[49] Vicente, E.; Villar, R.; Solano, B.; Burguete, A.; Ancizu, S.; Pérez-Silanes, S.; Aldana, I.; Monge, A. An. R. Acad. Nac. Farm., 2007, 73, 927.

[50] Zarranz, B.; Jaso, A.; Aldana, I.; Monge, A.; Maurel, S.; Deharo, E.; Jullian, V.; Sauvain, M. Arzneim.-Forsch., 2005, 55, 754.

[51] Zarranz, B.; Jaso, A.; Lima, L.M.; Aldana, I.; Monge, A.; Maurel S.; Sauvain, M. Braz. J. Pharm. Sci., 2006, 42, 357.

[52] Marín, A.; Lima, L.M.; Solano, B.; Vicente, E.; Pérez-Silanes, S.; Maurel, S.; Sauvain, M.; Aldana, I.; Monge, A.; Deharo, E. Exp. Parasitol., 2008, 118, 25.

[53] Vicente, E.; Charnaud, S.; Bongard, E.; Villar, R.; Burguete, A.; Solano, B.; Ancizu, S.; Pérez-Silanes, S.; Aldana, I.; Vivas,L.; Monge, A.. Molecules, 2008, 13, 69.

[54] Vicente, E.; Lima, L.M.; Bongard, E.; Charnaud, S.; Villar, R.; Solano, B.; Burguete, A.; Pérez-Silanes, S.; Aldana, I.; Vivas, L.; Monge, A.. Eur. J. Med. Chem., 2008, 43, 1903.

[55] Solano, B.; Junnotula, V.; Marín, A.; Villar, R.; Burguete, A.; Vicente, E.; Pérez-Silanes, S.; Aldana, I.; Monge, A.; Dutta, S.; Sarkar, U.; Gates, K.S. J. Med. Chem., 2007, 50, 5485.

[56] Zarranz, B.; Jaso, A.; Aldana, I.; Monge, A. Bioorg. Med. Chem., 2004, 12, 3711.

[57] Benson, C.A. Curr. Opin. Infect. Dis., 1994, 7, 95.

[58] Danelishvilli, L.; Bermudez, L.E. Curr. Pharm. Des., 2003, 9, 61. 


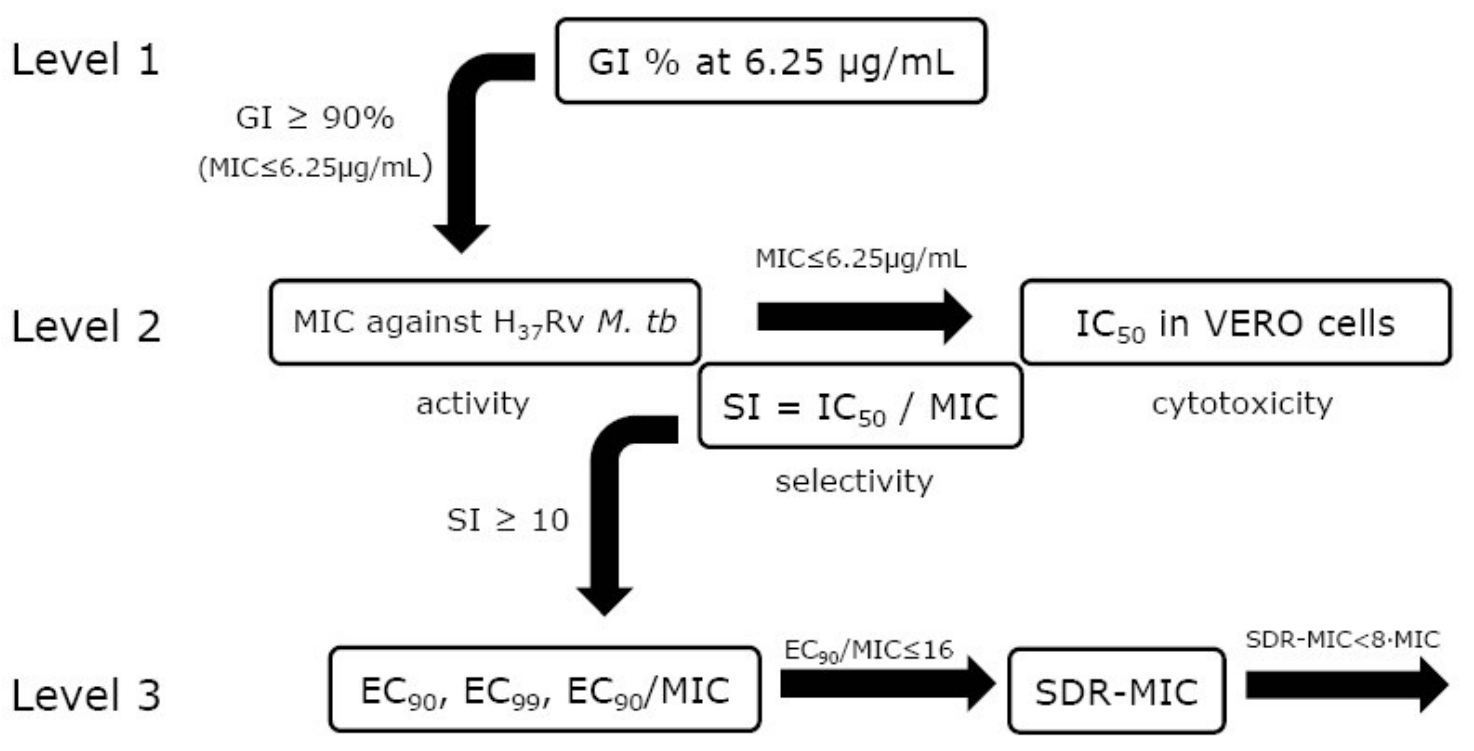

Chart 1. Testing levels and values used for moving compounds forward by TAACF. Level 1 testing determines the percent of growth inhibition (GI) for compounds; drugs having a Gl of > $90 \%$ or greater advance to level 2 . In Level 2 compounds are further selected on the basis MIC determination and selectivity index $(\mathrm{SI})$ and compounds with $\mathrm{SI} \geq 10$ move forward to more advanced testing. Level 3 measured activity against $M$. tuberculosis in the macrophage infection model and the $\mathrm{EC}_{90} / \mathrm{MIC}$ is determined. Level 3 also included testing against the single drug resistant strains (SDR-MIC) assays [9]. Together these data determine which compounds are testing for efficacy in animal models. 

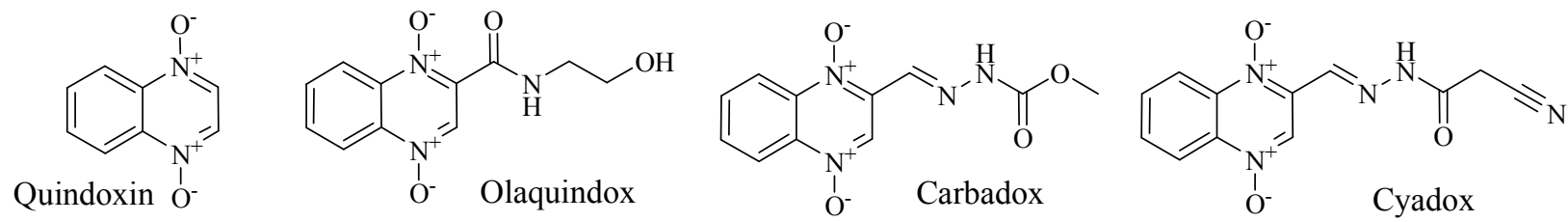

Figure 1. Chemical structures of quinoxaline 1,4-di- $N$-oxides used as animal growth promotors. 


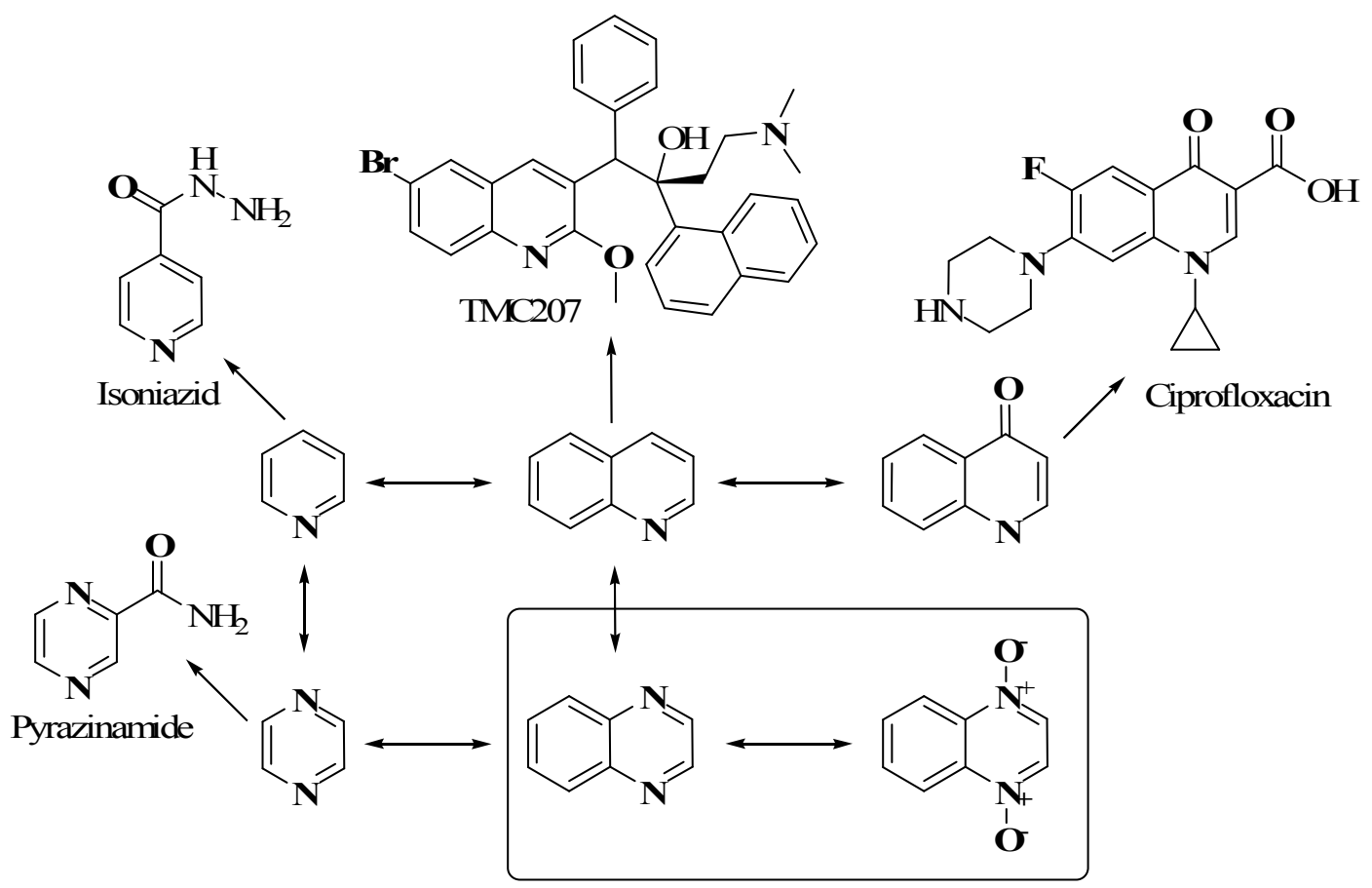

Figure 2. Scheme of chemical structural resemblance of antitubercular drugs. 


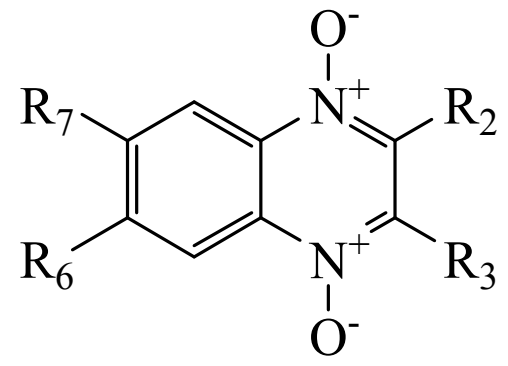

Figure 3. General structure of quinoxaline 1,4-di- $N$-oxide. 
<smiles>Cc1c(C(=O)Nc2ccccc2)[n+]([O-])c2ccccc2[n+]1[O-]</smiles>

1

$\mathrm{MIC}=3.13 \mu \mathrm{g} / \mathrm{mL}$

$\mathrm{SI}>20$

$\mathrm{EC}_{90} / \mathrm{MIC}=0.89$<smiles>Cc1ccccc1NC(=O)c1c(C)[n+]([O-])c2ccccc2[n+]1[O-]</smiles>

2

$\mathrm{MIC}=6.25 \mu \mathrm{g} / \mathrm{mL}$

$\mathrm{SI}>10$

$\mathrm{EC}_{90} / \mathrm{MIC}=0.42$<smiles>Cc1ccccc1NC(=O)c1c(C)[n+]([O-])c2ccc(Cl)cc2[n+]1[O-]</smiles>

3

$\mathrm{MIC}=6.25 \mu \mathrm{g} / \mathrm{mL}$ $\mathrm{SI}>10$

$\mathrm{IC}_{90} / \mathrm{MIC}=0.42$

Figure 4. 3-methyl- $N$-phenylquinoxaline-2-carboxamide 1,4-di- $N$-oxide derivatives. 
<smiles>CC(=O)c1c(C)[n+]([O-])c2ccccc2[n+]1[O-]</smiles>

4

$\mathrm{MIC}=3.13 \mu \mathrm{g} / \mathrm{mL}$

SI $>20$

$\mathrm{EC}_{90} / \mathrm{MIC}=0.87$<smiles>CC(=O)c1c(C)[n+]([O-])c2ccc(F)cc2[n+]1[O-]</smiles>

5

$\mathrm{MIC}=3.13 \mu \mathrm{g} / \mathrm{mL}$

$\mathrm{SI}>20$

$\mathrm{EC}_{90} / \mathrm{MIC}=0.79$<smiles>CC(=O)c1c(C)[n+]([O-])c2ccc(Cl)cc2[n+]1[O-]</smiles>

6

$\mathrm{MIC}=0.78 \mu \mathrm{g} / \mathrm{mL}$

$\mathrm{SI}>20$

$\mathrm{EC}_{90} / \mathrm{MIC}=3.13$

Figure 5. 2-acetylquinoxaline 1,4-di- $N$-oxide derivatives. 
<smiles>CCOC(=O)c1c(C)[n+]([O-])c2ccccc2[n+]1[O-]</smiles>

7

$$
\begin{gathered}
\mathrm{MIC}=1.56 \mu \mathrm{g} / \mathrm{mL} \\
\mathrm{SI}=30.13
\end{gathered}
$$$$
\mathrm{EC}_{90} / \mathrm{MIC}=0.56
$$<smiles>Cc1c(C(=O)OCc2ccccc2)[n+]([O-])c2ccccc2[n+]1[O-]</smiles>

9

$$
\begin{gathered}
\mathrm{MIC}=0.10 \mu \mathrm{g} / \mathrm{mL} \\
\mathrm{SI}=470
\end{gathered}
$$$$
\mathrm{EC}_{90} / \mathrm{MIC}=1.50
$$<smiles>CCOC(=O)c1c(C)[n+]([O-])c2ccc(Cl)cc2[n+]1[O-]</smiles>

8

$\mathrm{MIC}=0.20 \mu \mathrm{g} / \mathrm{mL}$ $\mathrm{SI}>50$

$\mathrm{EC}_{90} / \mathrm{MIC}=2.30$<smiles>Cc1c(C(=O)OCc2ccccc2)[n+]([O-])c2cc(Cl)ccc2[n+]1[O-]</smiles>

10

$$
\mathrm{MIC}=0.10 \mu \mathrm{g} / \mathrm{mL}
$$$$
\mathrm{SI}=76.9
$$

$\mathrm{EC}_{90} / \mathrm{MIC}=0.01$

Figure 6. Ethyl and benzyl 3-methylquinoxaline-2-carboxylate 1,4-di- $\mathrm{N}$-oxide derivatives. 
<smiles>[R2]c1ccc(Sc2c(C)[n+]([O-])c3cc([R2])c([R2])cc3[n+]2[O-])cc1[R7]</smiles><smiles>[R6]c1ccc(S(=O)c2c(C)[n+]([O-])c3cc([R2])c([R2])cc3[n+]2[O-])cc1[R17]</smiles><smiles>[R6]c1ccc(S(=O)(=O)c2c(C)[n+]([O-])c3cc([R])c([R])cc3[n+]2[O-])cc1[R7]</smiles><smiles>[R17]c1cc(Nc2c(C)[n+]([O-])c3cc(F)c(F)cc3[n+]2[O-])cc([R16])c1[R7]</smiles><smiles>Cc1c(NCc2ccccc2)[n+]([O-])c2cc(F)c(F)cc2[n+]1[O-]</smiles>

Figure 7. General structure of quinoxaline 1,4-di- $N$-oxide derivatives published by Carta's team in 2002 and 2004. 

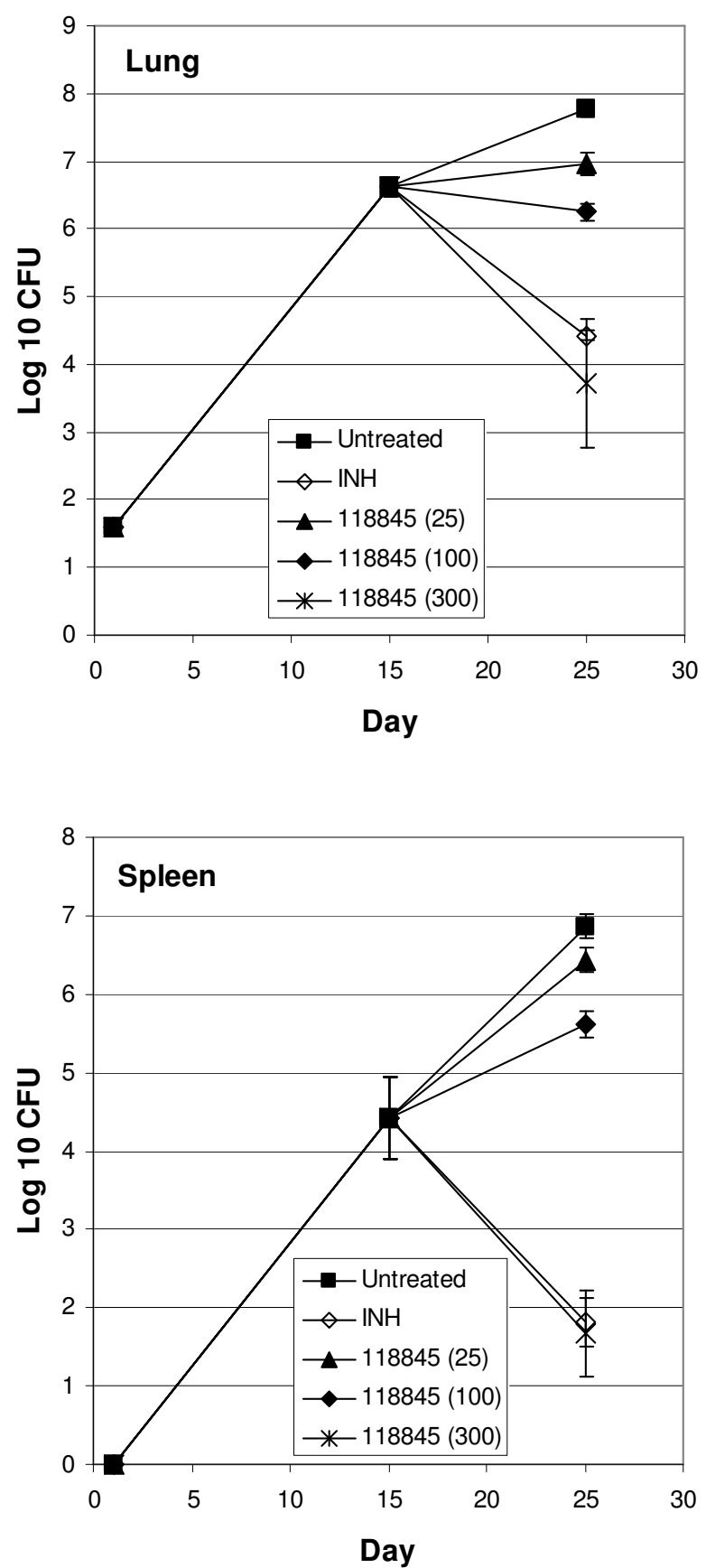

Figure 8. Dose response in vivo for compound 6, designed TAACF 118845. Mice were infected via low dose aerosol on day 0 . Following 15 days to allow the infection to establish, therapy was initiated once per day for 9 days. The next day mice were sacrificed and lung and spleen removed and homogenized and plated for CFU determination. CFU in infected mice on day 15 (the start of therapy) were also determined to establish the infectious burden at the initiation of therapy. 

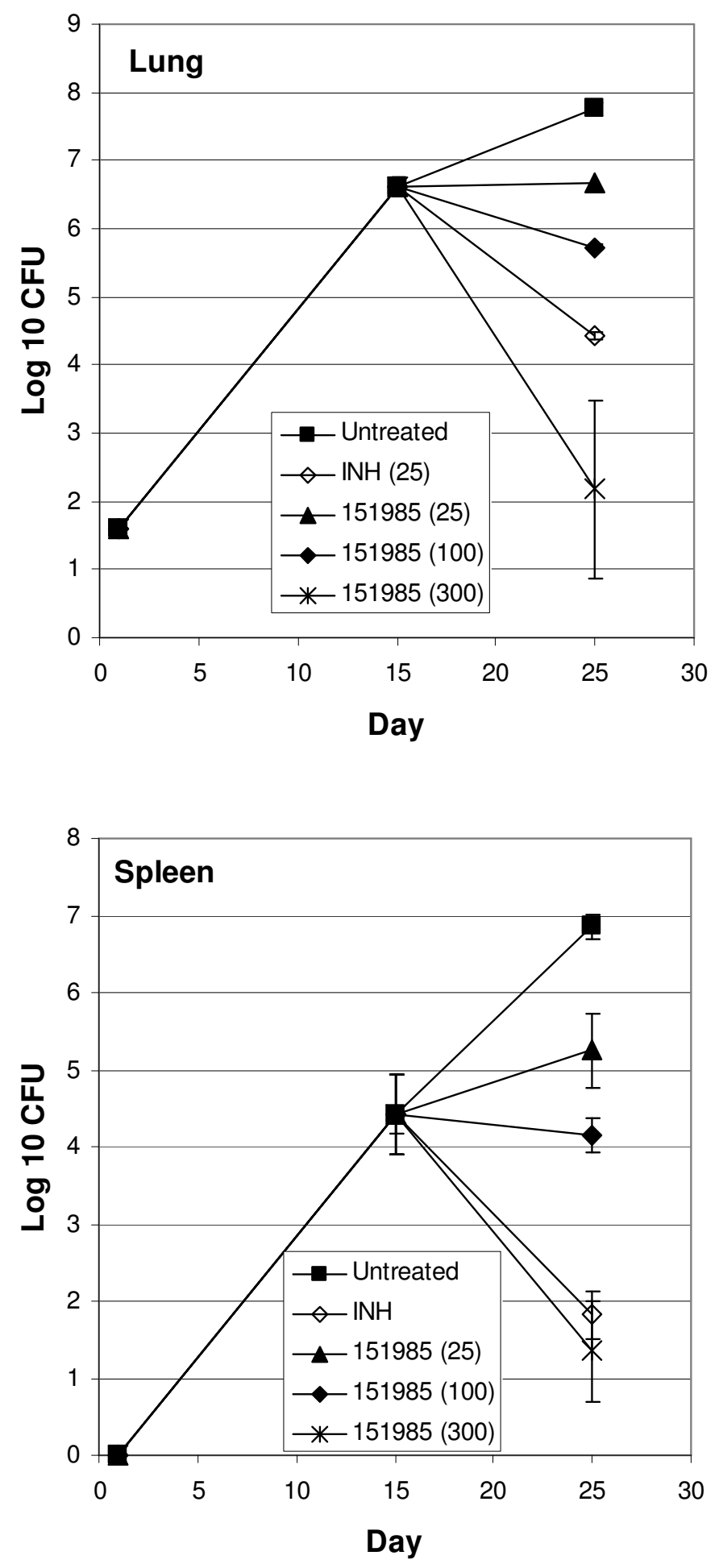

Figure 9. Dose reponse in vivo for compound 8, designated TAACF 151985. Procedures were identical to Figure 8. 
<smiles>CCOC(=O)c1c(-c2ccc(F)cc2)[n+]([O-])c2ccccc2[n+]1[O-]</smiles>

11

$\mathrm{MIC}=0.39 \mu \mathrm{g} / \mathrm{mL}$

$\mathrm{SI}=22.82$<smiles>CC(C)C(=O)c1c(C(F)(F)F)[n+]([O-])c2cc(Cl)c(Cl)cc2[n+]1[O-]</smiles>

12 $\mathrm{SI}<50$<smiles>[R]c1ccc2c(c1)[n+]([O-])c(-c1ccc([Al])cc1)c(C#N)[n+]2[O-]</smiles>

$13 \mathrm{R} 7=\mathrm{Cl} ; \mathrm{W}=\mathrm{F}(\mathrm{MIC}<0.2 \mu \mathrm{g} / \mathrm{mL} ; \mathrm{SI}>258)$

$14 \mathrm{R} 7=\mathrm{CH}_{3} ; \mathrm{W}=\mathrm{F}(\mathrm{MIC}<0.2 \mu \mathrm{g} / \mathrm{mL} ; \mathrm{SI}>500)$

$15 \mathrm{R} 7=\mathrm{OCH}_{3} ; \mathrm{W}=\mathrm{F}(\mathrm{MIC}<0.2 \mu \mathrm{g} / \mathrm{mL} ; \mathrm{SI}>475)$

$16 \mathrm{R} 7=\mathrm{F} ; \mathrm{W}=\mathrm{F}(\mathrm{MIC}<0.2 \mu \mathrm{g} / \mathrm{mL} ; \mathrm{SI}>124)$

$17 \mathrm{R} 7=\mathrm{F} ; \mathrm{W}=\mathrm{Cl} \quad(\mathrm{MIC}<0.2 \mu \mathrm{g} / \mathrm{mL} ; \mathrm{SI}>239)$

$18 \mathrm{R} 7=\mathrm{F}$; $\mathrm{W}=\mathrm{COOCH}_{3}(\mathrm{MIC}<0.2 \mu \mathrm{g} / \mathrm{mL}$; $\mathrm{SI}>258)$

Figure 10. In vitro lead-compounds of new series of quinoxaline 1,4-di- $N$-oxides. 